\title{
"Um bom estímulo à regeneração": a Penitenciária do Estado e as novas estratégias da ordem na Curitiba da Primeira República
}

Clóvis GRUNER ${ }^{\bullet}$

Resumo: Inaugurada em janeiro de 1909, a Penitenciária do Ahú, em Curitiba, é celebrada entre as autoridades e elites locais como "um atestado vivo do progresso". O projeto da penitenciária previa uma orientação pautada nos preceitos da penalogia moderna, que entendia o aprisionamento menos como castigo e mais como uma possibilidade de regeneração física e, principalmente, moral do criminoso. O objetivo deste artigo é acompanhar o percurso que, das primeiras reclamações e queixas diante do crescimento nos índices de criminalidade, culminam com a inauguração da Penitenciária. A intenção é, ao cruzar fontes locais - especialmente relatórios de polícia e de governo - com outras cuja origem e repercussão extrapolam os limites estaduais - tais como textos de juristas e criminologistas -, mostrar que a instituição penal celebrada pela imprensa e autoridades paranaenses, só pode ser compreendida se inserida em um contexto que não está contido nas linhas e entrelinhas dos discursos e políticas estritamente regionais.

Palavras-chave: Penitenciária; Disciplina; Crime; Criminalidade.

O medo, com sua física, tanto produz: carcereiros, edifícios, escritores, este poema; outras vidas.

Carlos Drummond de Andrade

\footnotetext{
- Doutorando em História - Programa de Pós-graduação em História Universidade Federal do Paraná - UFPR - 80060-000 - Curitiba - PR Brasil. Professor - Universidade Tuiuti do Paraná - UTP. E-mail: clovisgruner@terra.com.br
} 


\section{Introdução}

A experiência da modernidade é, também, aquela que inaugura uma nova forma de olhar. Herdeiro do racionalismo cartesiano e das luzes setecentistas, o século XIX ressignifica a metáfora que associa o olhar ao saber, o ato de ver à aquisição do conhecimento. Trata-se de uma mudança que é tanto de ordem quantitativa quanto qualitativa: em um mundo cada vez mais marcado e pautado por redes complexas de relações, a boa disposição das coisas será resultado de um olhar a um só tempo perspicaz e especializado, voltado não ao conjunto, mas ao detalhe. Ver de perto é ver mais e melhor.

É essa maneira de olhar e de saber, atenta aos sinais e indícios, que estabelece o que há de comum em disciplinas e discursos aparentemente tão distintos: a crítica de arte, com Morelli; a literatura policial, com os detetives Auguste Dupin e Sherlock Holmes, de Edgar Alan Poe e Conan Doyle, respectivamente; e a psicanálise de Freud, apropriam-se e fazem uso, cada um a sua maneira, do que poderíamos chamar aqui, parafraseando Ginzburg, do "método indiciário" proposto pela modernidade (GINZBURG, 1989: 181-205). Mas as possibilidades oferecidas por tal método não passam despercebidas, neste mesmo período, às forças policiais responsáveis por assegurar a ordem em meio ao caos em que se transformavam alguns dos principais centros urbanos da Europa oitocentista - Londres e Paris, por exemplo -, que rapidamente deixam a condição de "grandes cidades" para transformarem-se em "metrópoles".

A coincidência das datas não é casual: a segunda metade do século XIX, principalmente, vê acelerarem-se mudanças que estão sendo esboçadas desde algumas décadas antes. Mudanças que incidem principalmente no modo de vida das cidades, que aparecem, nos discursos científicos e nas narrativas literárias do período, como um espaço de admiração e medo: medo do outro em sua alteridade, mas também medo de uma multidão que aparece homogênea, sem rosto, indefinida. Mas se a multidão, por um lado, assegura o anonimato e este a 
"UM BOM ESTÍMULO À REGENERAÇÃO": A PENITENCIÁRIA...

proteção ao crime e ao criminoso; de outro ela representa um desafio ao olhar. Nas palavras de Haroche e Courtine, é "preciso poder distinguir-se, e o corpo de outrem torna-se uma colecção de detalhes a destacar, de índices a interpretar" (HAROCHE; COURTINE, 1995: 221).

Estas mudanças na maneira de olhar já foram observadas, entre outros, por Benjamin, que atribui aquele um papel fundamental para se entender as mutações advindas com a experiência da modernidade. Para o filósofo alemão, o ritmo intenso de algumas cidades européias produz um olhar saturado, incapaz de absorver imagens que, produzidas e apresentadas em um ritmo vertiginoso, não se deixam apreender em sua integralidade. Daí a mediação da técnica na apropriação da cidade pelo olhar e a importância da fotografia, que permite restabelecer o controle das coisas e, principalmente, das pessoas, lançando mão de artefatos mecânicos e tecnológicos cuja eficácia e precisão são consideradas soberanas em um tempo profundamente marcado pelo elogio à razão, à ciência e ao progresso (BENJAMIN, 1989: 33-45). Trata-se de aprimorar os mecanismos de um poder vigilante que incide tanto sobre o indivíduo, quanto sobre a população, regulamentando seus espaços, hábitos, costumes, instituindo códigos e normas de conduta. Em ambos, o corpo é o objeto privilegiado - corpo individualizado, certamente; mas também e principalmente corpo social, segmentado e permanentemente vigiado (FOUCAULT, 2000: 285-314).

E se é ao corpo que este olhar tecnologizado se dirige, não é por outro motivo se não para seqüestrá-lo de seu nomadismo e reinscrevê-lo em uma ordem onde ele será observado, estudado, tornado transparente. Trata-se de uma organização que ressignifica, em novos termos, a máxima da filosofia racionalista cartesiana: olhar é conhecer a coisa a ser conhecida em suas minúcias, em seus detalhes. A já citada fotografia, certamente, não é o único recurso técnico mobilizado nesta busca pela identidade do corpo. Uma miríade de novas metodologias é proposta no sentido de assegurar o suporte científico a esse olhar que, cada vez mais e mais, se especializa. Os nomes de HISTÓRIA, São Paulo, 28 (2): 2009 
Lombroso e Bertillon, positivistas, reverberam aqui. O primeiro foi o criador da antropologia criminal e da teoria do criminoso nato e o segundo, responsável pelo desenvolvimento da antropometria, à sua época considerada uma revolução nos métodos de identificação, criando um sistema cruzado de informações supostamente impermeável a qualquer falsificação.

Este percurso que, a partir do olhar, procura capturar o corpo vagabundo, não estaria completo sem a recorrência a um outro aparato, também técnico e igualmente amparado no discurso científico tão caro ao oitocentos. E se a fotografia e os demais métodos de identificação cumprem uma função seminal, qual seja, individualizar e identificar na multidão anônima o perigo, as prisões modernas vão desempenhar uma função em tudo complementar: caberá a elas assegurar, pelo seqüestro destes corpos do espaço público e seu enclausuramento, sua vigilância, disciplina e regeneração.

Em "Vigiar e punir", Michel Foucault procura articular o nascimento da prisão hodierna e das novas tecnologias de dominação à emergência do que chama de "moderna era do controle social", localizando-a entre fins do século XVIII e início do XIX. Para o filósofo francês, as prisões não nascem como signos do progresso e da humanização propostos pelo iluminismo, nem tão pouco são desdobramentos "lógicos" do abandono da barbárie do suplício, advindos com a Revolução Francesa (FOUCAULT, 1987: 11-65). Atento às descontinuidades históricas, ele mostra que elas resultam da sofisticação nas formas de controle e exercício da violência, tese aliás que ele já apresentara, ainda esboçada, nas célebres palestras ministradas no Brasil em 1973. É nelas também que Foucault apresenta um dos pressupostos onde se assenta a disciplina prisional e que adquire um estatuto mais amplo quando articulado às mudanças sociais e econômicas advindas com a modernidade: refiro-me aqui ao controle do corpo, que no interior das prisões "deve ser formado, reformado, corrigido (...) deve adquirir aptidões, receber um certo número de qualidades, qualificar-se como corpo capaz de trabalhar" (FOUCAULT, 1996: 79-126). Estas aspiração serviu, ao longo do século XIX, de referência e 
"UM BOM ESTÍMULO À REGENERAÇÃO": A PENITENCIÁRIA....

inspiração para que antigas instituições, na Europa e nos EUA, fossem remodeladas e novas construídas. Nascia a prisão moderna.

\section{Um novo Código, muitas reformas}

A influência destes novos modelos de vigilância e punição atravessou o Oceano e veio alojar-se em terras brasileiras, onde suas idéias foram adotadas quase que simultaneamente ao Velho Mundo. Assim, apesar das controvérsias - alguns juristas e criminalistas o consideravam um tanto eivado demais pelos princípios da escola clássica -, em outubro de 1890 é instituído o Código Penal do Brazil, o primeiro da República. Ele como que autoriza e legitima a série de inovações técnicas e institucionais que passariam a ser incorporadas ao aparato policial e jurídico nos anos subseqüentes, em parte como uma forma de compensar o descompasso, ou mesmo a defasagem, entre o que se esperava dele e aquilo que ele de fato veio a ser. A sua e recepção, no entanto, devem ser pensadas em um contexto um pouco mais amplo, especialmente porque as discussões que resultam na nova lei penal começam pelo menos duas décadas antes, no outono do Império e em meio a discussões exaltadas acerca do futuro político do país. Para muitos autores, as décadas que antecedem o novo regime são, por assim dizer, de "preparação" para o advento das mudanças que viriam a ser implementadas, muitas delas à força, na virada do século XIX e nas décadas subseqüentes. Para Herschmann e Pereira ao "longo do período 1870-1937, assistimos ao desenvolvimento de várias estratégias de construção de um novo ordenamento político-cultural nacional, de uma República capaz de romper com o esquema das oligarquias regionais, consagrando assim, definitivamente, a emergência de uma sociedade urbanoindustrial" (HERSCHMANN; PEREIRA, 1994: 12).

A promulgação do Código Penal aparece, então, como um dos desdobramentos de uma tríade - trabalho, ordem e progresso - sobre a qual se assenta a república recém instituída. 
É ela quem alimenta o imaginário moderno das nem tão novas elites, estabelecendo seus limites e fronteiras. Grosso modo, se à utopia da modernidade corresponde a necessidade da ordem, a segurança aparece no interior daquela aspiração como um elemento fundamental, do qual dependerá a proteção da sociedade contra toda futura desordem.

Não que o Código Penal, por si só, representasse essa garantia. Em torno dele, aliás, sucedem-se críticas, especialmente dos partidários do direito positivo, que apontam o seu descompasso em relação aos avanços e as conquistas da "moderna ciência criminológica". Descompasso que é, em parte, resultado do próprio hibridismo de que resulta a nova lei penal. Embora incorpore algumas das críticas ao antigo Código do Império, datado de 1824, o código republicano, de acordo com os positivistas, está ainda por demais arraigado nos princípios da escola clássica e seus conceitos "idealistas" e pouco "científicos".

O contraponto a estas tendências tidas como "metafísicas" e "abstratas" virá do "direito positivo" então em voga na Europa e estimulado, principalmente, pelas pesquisas desenvolvidas por Lombroso e seus discípulos, fundadores da antropologia criminal e que defendem a cientificização e medicalização do crime. Uma mudança de perspectiva para com o crime, mas também um novo olhar sobre o criminoso. Se é possível, de acordo com Lombroso, identificar a tendência ao crime por características físicas inatas ao indivíduo, o Estado e as instituições responsáveis pelo encarceramento mudam também sua orientação. Em tese, o caráter meramente punitivo das prisões é insuficiente para dar conta do que deveria ser seu objetivo: regenerar o indivíduo para sua reintegração à sociedade, se possível; ou torná-lo dócil, domesticando seus impulsos agressivos, quando a regeneração mostrava-se impraticável. Dentro desta ótica, o isolamento e a ociosidade das prisões contribuíam para degenerar ainda mais aquele que já é, por sua própria constituição, um degenerado. Não se tratava, portanto, de modificar a "natureza" do criminoso, mas de educálo de acordo com os valores considerados moralmente sadios. Às 
"UM BOM ESTÍMULO À REGENERAÇÃO": A PENITENCIÁRIA...

instituições penais caberia, então, um papel pedagógico. Uma pedagogia toda ela construída sob o signo da ordem e da disciplina e que tem, no trabalho, seu principal instrumento de regeneração (DARMON, 1991: 35-51).

\section{A ordem que precede o progresso}

A inserção de Curitiba no chamado projeto burguês de sociedade remonta a meados do século XVIII e atravessa o XIX. Essa mudança é, inicialmente, parte de uma ação mais ampla de controle da metrópole, Portugal, sobre a Colônia, suas províncias e vilas, que se inicia e consolida ao longo do setecentos e se estende até a independência. $O$ governo imperial trata de assegurar a continuidade dessa política, e algumas cidades passam a contar com uma administração pública mais "eficiente", preocupada com a organização e higiene públicas, instituindo códigos e regulamentos voltados à concretização destes fins (BURMESTER, 1987: 177-205; PEREIRA, 1996: 98177). Mas é o advento da república que imprime de forma definitiva um ritmo acelerado de mudanças e inovações, e não apenas no caráter urbanístico das cidades. A capital do ainda jovem estado do Paraná, certamente, não é exceção e, desde fins do século XIX e ao longo dos primeiros anos do século seguinte, a cidade passa por uma série de intervenções que visam, fundamentalmente, melhorar seu traçado urbano, emprestandolhe um ar mais moderno e "civilizado".

É verdade que Curitiba não era exatamente uma metrópole. Mas os ares modernizantes e modernizadores que já se faziam presentes, e a própria maneira como ela era lida não só pelas elites, mas também e principalmente pela inteligência local, lançam luz sobre uma tendência a falar da capital paranaense como uma urbs cosmopolita, a ombrear com o que de melhor a civilização moderna produzia em termos urbanísticos. Trocando em miúdos, no imaginário que perpassa essas camadas sociais, há um acento significativo naquelas 
características que fazem da capital um lugar moderno, no duplo sentido da palavra: nos esforços e investimentos públicos para se "modernizar" o traçado urbano; mas também naqueles hábitos e costumes que caracterizam a "modernidade". Nas palavras de Elizabete Berberi, viver em uma cidade como Curitiba na virada do século "implicava em tomar contato com novas experiências que se apresentavam e com expectativas que se projetavam de um grau de civilização desejado" (BERBERI, 1998: 1).

Nesse sentido, parece ficar claro outro aspecto que, aparentemente contraditório, é na verdade parte integrante do imaginário urbano deste período, aqui e fora: se, por um lado, a modernidade trouxe o progresso e a civilização, ela engendrou também o seu avesso: a violência e o crime. Mas não é só. O próprio aumento nos índices de criminalidade, que a imprensa curitibana acusava no alvorecer do século XX, denuncia que as conquistas do mundo moderno podem servir também às artimanhas dos "individuos perigosos e merecedores dos castigos legaes". O acesso ao admirável mundo novo da modernidade, com seu aparato técnico-científico e suas cidades repletas de becos e ruelas escuros, verdadeiros labirintos urbanos, fez facilitar e ampliar a degenerescência criminosa. E se os novos instrumentos de criminalidade foram forjados no interior da civilização moderna, é nela também que os homens e mulheres virtuosos encontrariam os "recursos valiosos, eficazes, capazes de, mais que a repressão penal, atenuar os efeitos, diminuir os sucessos, combater os resultados da criminalidade contemporânea" (CANCELLI, 2001: 93). Um policiamento mais eficaz e aparelhado é por certo uma das alternativas. ${ }^{1}$ Mas não a única e nem sempre a mais eficiente.

Algumas ações no sentido de assegurar a ordem e a segurança públicas começam, então, a ser tomadas. Em março de 1903 a cidade vê inaugurar o Hospício de Nossa Senhora da Luz, no Ahu, um dos "mais brilhantes passos no caminho do progresso e da civilisação". ${ }^{2}$ Embora destinado prioritariamente ao internamento e tratamento dos alienados, já no dia seguinte à inauguração o "Diário da Tarde" noticia que um acordo firmado 
"UM BOM ESTÍMULO À REGENERAÇÃO": A PENITENCIÁRIA...

entre o prefeito, o chefe de polícia e a administração do nosocômio prevê a criação de um espaço destinado ao recolhimento dos mendigos, tanto o das ruas quanto aqueles que se encontram detidos nas cadeias da cidade. Para assegurar de vez a "limpeza" da cidade, um edital proibindo a prática da mendicidade é publicado no mesmo dia. ${ }^{3}$ Dois anos depois, em abril de 1905, começa a funcionar o Gabinete Antropométrico, que utiliza como método de identificação o sistema de Bertillon. Contemporâneos destes investimentos, como a demonstrar uma ação orquestrada por parte do estado com o intuito de modernizar e fortalecer o aparato de segurança, são a implantação ou revisão dos regimentos e regulamentos das prisões, da Estatística Policial e Judiciária, da Repartição Central de Policia, do Regimento de Segurança e a Consolidação das leis policiais, esta última datada de 1909, mesmo ano da inauguração da penitenciária.

Nenhuma destas ações, no entanto, tocava em um problema central, para cuja solução reclamavam-se medidas urgentes desde o final do século anterior. Malgrado os esforços para a construção de uma penitenciária estadual nos derradeiros anos do império (STRAUBE, 2005: 273), o que se reivindicava naquele momento era uma prisão que não apenas comportasse o número de criminosos que, vindos de todo o estado, habitavam as celas fétidas das cadeias locais, mas que contribuísse efetivamente para sua recuperação. Em seu relatório de 1898, o chefe interino de polícia, Major Augusto Silveira de Miranda, pedia a construção de uma penitenciária como recurso imprescindível ao melhoramento da segurança no Paraná. Diz ele que

(...) A construção de uma penitenciaria nessa capital torna-se uma necessidade urgente, pois [em] nossas actuaes cadeias achão-se reunidos em uma mesma celulla presos de idade e estados diferentes.

Comunicando-se os seus vícios e defeitos e respirando um ambiente de perversão moral, que faz com que indivíduos entrão nas prisões corrompidos e sahião d'ellas gangrenados. $(. . .)^{5}$ 
CLÓVIS GRUNER

Dois anos depois, era a vez do próprio secretário de Negócios de Interior e Justiça e Instrução Pública, Octavio Ferreira do Amaral, em relatório enviado ao presidente do Estado, atentar para o descompasso da segurança pública no Paraná com as possibilidades renovadoras preconizadas pelo Código Penal republicano: "Como sabeis o nosso Código Penal (...), nos seus artigos 43 e seguintes institui o sistema progressivo ou da diferenciação da pena, de Walter Crofton. (...) São decorridos 10 anos daquela data e ainda não pudemos por em execução o moderno sistema penitenciário." 6

As queixas das autoridades repercutem na imprensa, especialmente no "Diário da Tarde", principal jornal do período, cuja linha editorial, um tanto mais independente que 0 concorrente "A República", permitia um conteúdo mais ácido no tratamento do tema em suas matérias e editoriais. Antes que as primeiras medidas de modernização do aparato de segurança, anotadas logo acima, começassem a aparecer, um dos cronistas do vespertino lamenta que é "deveras entristecedor o quadro da estatística dos crimes que se verificam neste Estado, e nomeadamente nesta capital". E prossegue constatando que, apesar da ainda pequena população, o "Paraná no entanto assiste ao desenrolar contínuo de crimes sobre crimes". Ao final, uma pergunta e uma sugestão:

Qual a causa desse estado mórbido da nossa sociedade?

Conviria aos espíritos que se dedicam ao estudo desse difficil ramo da sciencia social - a anthopologia criminal - procurassem investigar das origens dessa serie de crimes, que reflectem tão vivamente sobre a tranquilidade pública, levando o desassocego aos lares e o temor aos corações pusilanimes.

Só assim poder-se-ia, conhecendo as causas, evitar os seus terríveis effeitos. $^{7}$

Não deixa de ser interessante observar que a mesma ciência reivindicada pelo jornalista para investigar o crime, "conhecendo as causas" para evitar os seus "terríveis effeitos", 
"UM BOM ESTÍMULO À REGENERAÇÃO": A PENITENCIÁRIA...

aparece nos discursos anteriores, ainda que em outro contexto: se neste ela permite o diagnóstico, naqueles seu uso é indicativo de regeneração. Nos três, é de um estado de "morbidez social" que estão a falar autoridades e jornalistas, mesmo quando as referências ao mal e a sua cura aparecem veladas, como é o caso dos discursos do chefe de polícia e do secretário de estado em seus respectivos relatórios.

A sintonia local revela uma outra, mais ampla e significativa. Desde os últimos anos do século anterior, em parte impulsionada pela proclamação da República, há uma movimentação intelectual significativa, no Brasil, em torno à constituição de um pensamento jurídico e criminológico que dialoga, de muito perto, com as novas tendências e idéias em voga na Europa. Não é o caso aqui de se apresentar e discutir, de forma detalhada, aquelas novas tendências e idéias, bem como sua recepção em terras tupiniquins. Basta dizer que a introdução do novo pensamento jurídico e penal no país não se faz de forma homogênea e que não há, em torno a ele e entre seus divulgadores nacionais, nem anuência e tão pouco um consenso absoluto. Em seu estudo sobre a constituição da criminologia no Brasil, Marcos Alvarez chama a atenção tanto para as críticas que recebem de seus leitores brasileiros os "pais" da criminologia moderna - Lombroso inclusive - quanto às divergências de leituras e interpretações entre os juristas e criminologistas locais (ALVAREZ, 2003: 53-82; 117-130).

Estas diferenças, no entanto, não eliminam completamente alguns elementos comuns. Entre eles, a convicção de que a "nova escola penal" e o que dela deriva são científicos. E é com a autoridade que a ciência lhe confere que ela se lança à tarefa de não apenas formular um novo conceito, mas oferecer novas e efetivas medidas de combate ao crime e à criminalidade. Decorre daí, em grande parte, o esforço político empreendido no sentido de conferir ao novo Código Penal um conteúdo coerente com os princípios teóricos que norteavam o direito positivo, em oposição ao direito clássico, que orientava o Código Criminal do Império. 
Apesar disso, como já dito, quando promulgado em 1890 o Código republicano estava longe de ser unanimidade entre juristas e criminalistas. Para Fernando Salla, ele "não aparece como a conseqüência da incorporação destas inovadoras tendências que o mundo jurídico-penal apresentava. E nem mesmo foi o desdobramento lógico do novo regime político, republicano, que se implantava." Mas se por um lado a nova lei penal não atendia integralmente as expectativas de juristas e criminologistas ligados ao direito positivo, por outro ela como que autoriza e legitima a série de inovações técnicas e institucionais que passariam a ser incorporadas ao aparato policial e jurídico brasileiro nos anos subseqüentes, em parte como uma forma de compensar o descompasso, ou mesmo a defasagem, entre o que se esperava dela e aquilo que ele de fato ela veio a ser. As primeiras prisões republicanas, por exemplo, tentam cumprir esta função. De acordo ainda com Salla, as teorias positivistas serviram

de esteio para justificar as práticas de gestão e operação nas instituições que surgiram na passagem do século, além de respaldar a intervenção do Estado junto à sociedade no contexto dos controles e inserções que promovia por meio destas instituições. (...) O Estado republicano (...) é assim peça fundamental no delineamento da ordem pública. (...) E isto se dava, entre outras coisas, por meio da implantação de uma rede de instituições especializadas, mas ao mesmo tempo articuladas, destinadas a alcançar, incorporar e controlar setores cada vez mais amplos da sociedade (SALLA, 1999: 145-151).

Não por acaso Elysio de Carvalho, um dos principais divulgadores da "polícia científica" no Brasil defendia, por esta mesma época, a necessidade de uma estrutura policial e penal mais eficiente e moderna, capaz de suportar as mudanças pelas quais passava a sociedade brasileira, notadamente nas suas principais cidades, que por motivos óbvios eram as primeiras a sentirem os efeitos de um crescimento tão necessário e desejado quanto temido. Para o teórico carioca as prisões, antes um 
"UM BOM ESTÍMULO À REGENERAÇÃO": A PENITENCIÁRIA...

"regimen de terrores, martyrios e vexames de toda sorte", tornaram-se, por força e influência da ciência criminal moderna "não um castigo, mas uma especie de remédio capaz de preservar, curar, attenuar a criminalidade, afim de que a ordem jurídica conserve o luminoso e perfeito equilíbrio, sem o qual a planta humana não poderá viver, desenvolver-se, fructificar" (CARVALHO, 1910: 9-10). Repercutindo Garofalo, criminalista italiano e um dos principais teóricos da antropologia criminal, ao lado de Lombroso e Ferri, para quem o "meio penal deve ser determinado pela possibilidade de adaptação do réu, isto é, pelo exame das condições de existência em que pode presumir-se que elle cesse de ser temível" (GAROFALO, 1908: 346. Grifos no original), Carvalho mostra-se também em consonância com outros criminologistas e juristas brasileiros que, com diferenças mais ou menos sutis, vinham há anos defendendo reformas urgentes no sistema penitenciário, tido por obsoleto e anacrônico mesmo em relação aos avanços, mesmo que tímidos, propostos pelo Código de $1890 .^{8}$ Para determinados críticos era necessário, no mínimo, adequar as prisões brasileiras, reformando as já em funcionamento e, se necessário, construindo novas onde a mera reforma se mostrasse inviável, ao que determinava o Código em seus artigos 43 a 45 - que instituam a pena de prisão celular e as condições necessárias ao seu funcionamento - e o 53, que obrigava o Estado a garantir ao sentenciado, "nos estabelecimentos onde tiver de cumprir a pena, trabalho adaptado ás sua habilitações e precedentes occupações."

Híbrido em seu arcabouço teórico, que congregava elementos da Escola Penal Positiva - tais como a concepção de que a pena, especialmente a de reclusão, visava não apenas a punição do crime, mas especialmente a possibilidade de recuperação do criminoso - sem renunciar completamente aos pressupostos da Escola Clássica - como, por exemplo, o entendimento sutil de que a ação criminosa é fruto da vontade soberana de um indivíduo livre e consciente - o Código também o era no modelo de regime penitenciário proposto pelos legisladores como adequado à regeneração do criminoso. Este 
incorporava características de três modelos distintos, forjados ao longo do século XIX na Europa e nos Estados Unidos: os sistemas de Filadélfia, Auburn e o Irlandês ou Progressivo. E se a primeira penitenciária integralmente construída segundo os preceitos da lei penal só apareceria em 1920, com a inauguração da Penitenciária do Carandiru, em São Paulo, não faltaram ao longo das três décadas entre a promulgação do Código e o funcionamento da instituição modelo da capital paulista, tentativas de viabilizar instituições de reclusão em maior ou menor grau inspiradas na matriz "científica" preconizada na lei (PEDROSO, 1997: 121-137).

A Penitenciária do Ahu surge, neste contexto, como expressão de uma vontade política das elites locais de assegurar, por seu intermédio, não apenas um meio de punição e regeneração de criminosos; mas também o ingresso de Curitiba no rol das cidades equipadas para combater os males da "morbidez social" com as armas da modernidade e da civilização.

Inaugurada em janeiro de 1909 e posta em funcionamento em abril, ela ocupa um lugar fronteiriço nos esforços do ainda recém emancipado estado do Paraná. De um lado, ela é o desdobramento de um processo que atribui, ao crime e à criminalidade $^{10}$, uma maior visibilidade, especialmente na imprensa, resultando na reivindicação crescente de um aparato policial coerente com o status de uma cidade erigida à condição de capital há pouco mais de meio século (GRUNER, 2003: 67-94). De outro, ela é também a instituição em torno da qual novos e mais significativos esforços do poder público visam criar, não apenas uma instituição policial mais moderna e eficiente, mas toda uma estrutura jurídica e penal coerente com o discurso modernizador e positivista que grassava pelo país, informando entre outros, o campo do direito e da criminologia. 
"UM BOM ESTÍMULO À REGENERAÇÃO": A PENITENCIÁRIA...

\section{"Um utilíssimo estabelecimento"}

Um acordo firmado em abril de 1905 entre o secretário de Estado dos Negócios, Obras Públicas e Colonização do Paraná, Francisco Beltrão, e o provedor do Asilo de Alienados, Monsenhor Alberto José Gonçalves, previa a cessão, por parte do segundo, do prédio do asilo para a instalação da Penitenciária do Estado; em troca, o governo estadual auxiliaria a Santa Casa de Misericórdia na construção de uma nova sede para abrigar o hospício. ${ }^{11} \mathrm{O}$ modelo a ser adotado seria definido de acordo com as necessidades e conveniências do "meio".

$\mathrm{O}$ anúncio de que medidas mais efetivas seriam tomadas para a solução do problema prisional foi feito em fevereiro, em mensagem do presidente do Estado, Vicente Machado, aos deputados paranaenses na abertura dos trabalhos legislativos daquele ano. Acusando as péssimas condições da cadeia pública da capital, Machado enfatiza a urgência de uma ampla reforma prisional e pede aos deputados que lhe concedam "os meios para attender esse serviço e remover os inconvenientes apontados. Exigem-n'os os deveres de governo e até os de simples humanidade". ${ }^{12} \mathrm{O}$ apelo dramático, no entanto, não resulta necessariamente em eficiência. Decorridos dois anos do acordo, o Secretário dos Negocio do Interior, Justiça e Instrução Pública, Lamenha Lins, critica pouco sutilmente a demora do poder público em fazer funcionar as novas instalações penitenciárias. A crítica se estende ao contrato entre o governo e a Santa Casa, que o secretário considera, além de oneroso ao erário, um entrave a mais na já longa espera pela nova instituição. ${ }^{13}$

No ano seguinte é enfim sancionada a lei que autorizava a constituição da Penitenciária do Estado, ao mesmo tempo em que criava e instituía o seu regulamento. ${ }^{14} \mathrm{Em}$ seu relatório anual, o secretário de Obras Públicas e Colonização, Claudino Rogoberto Ferreira, justifica a demora na entrega da instituição apesar do acordo, firmado quase quatro anos antes, visar justamente o contrário. De acordo com o secretário 
(...) o edifício em questão [do Asilo de Alienados] não podia por sua natureza ser facilmente adaptado a uma Penitenciaria e por maiores que tivessem de ser as despezas a realisar nesse intuito, jamais se chegaria à obtenção de um estabelecimento modelar, conforme convinha. (...) Grandes reformas foram necessárias realisar e ainda assim o numero de cellas é diminuto, a segurança do prédio não póde ser considerada rigorosa e há a observar a ausência da muralha de retorno (.... ${ }^{15}$

As ressalvas de Rogoberto Ferreira não impedem que em janeiro de 1909, com a remoção dos primeiros presos da cadeia civil, a Penitenciária do Ahu finalmente entre em funcionamento, tendo sido nomeado seu primeiro diretor o major Ascanio Ferreira de Abreu. O modelo adotado foi o de Auburn, que preconizava a regeneração do criminoso por meio do trabalho diurno fora das celas, executado de forma contínua e silenciosa e, durante a noite, isolamento total até o alvorecer do novo dia. As reservas do secretário de obras, inclusive, parecem não contaminar seu colega de governo, Luis Antonio Xavier, titular da pasta a qual estava subordinada a direção da Penitenciária, a do Interior, Justiça e Instrução Pública. No seu relatório ele dá as boas vindas à instituição, que apresenta como uma "prisão hygienica onde o recluso se não habitue a ociosidade e ao contrario se affeicoe ao trabalho e que exerça sobre elle benéfica influência"; e para que se cumprisse tal intento explica que "desde logo serão montadas oficinas de alfaiataria e marcenaria, além de uma secção de typographia e de encadernação." $\mathrm{E}$ apesar da observação de que "a lotação actual não pode exceder de 52 condenados pela necessidade legal da segregação noturna" ${ }^{16}$, já nos primeiros meses, 55 presos - 49 homens e seis mulheres, todos homicidas - ocupavam as 52 celas da instituição. O entusiasmo alcança o Procurador Geral da Justiça, que em seu relatório de 1910 fala da penitenciária como um "utilíssimo estabelecimento (...) attestado vivo de progresso do Paraná". ${ }^{17}$ 
"UM BOM ESTÍMULO À REGENERAÇÃO": A PENITENCIÁRIA...

Enfronhado diuturnamente no cotidiano da instituição, o primeiro relatório do diretor da penitenciária, Ascanio de Abreu, soa mais equilibrado que os de seus superiores. Ainda que faça dos 11 meses de regime um balanço positivo - o que, levando-se em conta o lugar de onde proferia seu discurso não podia ser diferente, pois quem falava não era tanto o sujeito, mas a instituição da qual ele era um representante formal e oficialmente nomeado - faz questão de enfatizar a urgência de alguns investimentos, necessários ao seu melhoramento. Além da lotação excedente, já observada pelo secretário Xavier, reivindica a construção de uma muralha em torno ao edifício, para impedir ou ao menos diminuir o risco de fugas e recepção de objetos não permitidos pelo regulamento, o aumento no número de guardas e a construção de dois novos pavilhões, destinados um à enfermaria e outro às oficinas de alfaiates, sapateiros e tipógrafos, "que se acham pessimamente installadas em salas improprias e acanhadas".

De todos os problemas apontados, no entanto, sem dúvida é o risco de superlotação que mais preocupa o diretor. E não sem motivo: um dos critérios fundamentais ao funcionamento do modelo Auburn é a garantia do trabalho comum diurno, que deve ser conduzido sob um silêncio rigoroso, assegurado pela vigilância constante, conjugado à prisão celular noturna - e mesmo diurna para os presos pouco afeitos ao labor (CHAVES, 1923: 205-209). Mais homens que celas disponíveis significaria, inevitavelmente, comprometer as intenções expressas na própria concepção do projeto, inibindo a instituição de "resolver o problema das necessidades actuaes do Estado, relativamente ao número sempre crescente de transviados do caminho do bem, desses desventurados habitantes das cellulas". ${ }^{18}$

E se a importância dada ao trabalho soa óbvia em uma sociedade assentada nos valores burgueses, para quem o ócio é já expressão de uma degenerescência que seria preciso, se não curar, ao menos combater, a exigência da solidão merece aqui uma rápida explicação. Comentando a estreita relação entre isolamento e disciplina nos modelos penitenciários modernos, Michel Foucault notou que por meio daquele é possível 
assegurar "a submissão total (...) o encontro do detento a sós com o poder que se exerce sobre ele". Além disso, a solidão do isolamento exerce "uma espécie de auto-regulação da pena, e permite uma como que individualização espontânea do castigo: quanto mais o condenado é capaz de refletir, mais ele foi culpado de cometer seu crime; mas mais também o remorso será vivo, e a solidão dolorosa; em compensação, quando estiver profundamente arrependido, e corrigido sem a menor dissimulação, a solidão não lhe será mais pesada" (FOUCAULT, 1987: 212). Num certo sentido, isolar o corpo tem um significado oculto, não expresso: tornar mais frágil e alquebrada a alma, estágio final de uma docilização que, ao fim e ao cabo, visa a produção de uma subjetividade dócil e submissa. Em outras palavras: a sujeição constitui o sujeito. O sujeito, constitui-se pela sujeição.

Os apelos do major Ascanio de Abreu, no entanto, não encontram o respaldo necessário. Seja pelas dificuldades financeiras ou por simples vontade política, em um curto espaço de tempo a situação da penitenciária se deteriora e, pouco a pouco, torna-se cada vez mais difícil manter em vigor o projeto original. Antes de seu $10^{\circ}$ aniversário, em 1917, já são 122 sentenciados - mais de dois para cada cubículo. Segundo Maria Ignês de Boni, a "superlotação, que alterava a disciplina, e a carência de recursos para por em funcionamento as oficinas, levaram as autoridades a novamente se referirem à 'prisão promiscua', 'escola de crime' (...)"(BONI, 1998: 75). Uma das alternativas propostas é a criação de uma casa de detenção, voltada ao recebimento e reclusão dos presos pronunciados, o que só viria a acontecer em meados da década de 1920 - o prédio para a detenção é adquirido em 1923 e a instituição entra em funcionamento dois anos depois. 
"UM BOM ESTÍMULO À REGENERAÇÃO": A PENITENCIÁRIA...

\section{Apontamentos para uma (in)conclusão}

No balanço que faz dos primeiros meses de funcionamento da penitenciária, e depois de chamar a atenção de seus superiores para os problemas cuja solução demanda investimentos urgentes, o major Ascânio Ferreira de Abreu dedica uma especial atenção ao progresso físico dos sentenciados: "Os penitenciados, em geral", afirma, "estão robustos, e com o regimen de trabalho a que estão sujeitos, de rachiticos que eram, doentios pela completa ociosidade em que viviam e pela falta dos mais comesinhos preceitos de hygiene, tiveram as forças restauradas, apresentando-se com um aspecto sadio e com aproveitável desenvolvimento muscular". E arremata: "O trabalho bem distribuído e a instrucção bem ministrada, eis a meu ver, os vehiculos que com mais segurança e rapidez percorrem a grande estrada do reerguimento physico e moral dos delinqüentes." 19

A atenção ao corpo é coerente com a preocupação que fundamenta e justifica o projeto penitenciário moderno. Ainda que boa parte dos esforços do novo sistema penal se volte à regeneração moral do delinqüente - daí a ênfase na educação e no trabalho -, é inequívoco que à correção da "alma" corresponde um investimento naquilo que Foucault denominou "ciência do corpo". E não se trata simplesmente de um atalho chegar ao interior pelo exterior -, mas de políticas que se complementam e que cumprem funções isonômicas. Falando sinteticamente, o caráter meramente punitivo das prisões é insuficiente para dar conta do que deveria ser seu principal objetivo: punir apenas, não mais! Era necessário investir na regeneração do indivíduo e em sua reintegração à sociedade. Não se trata, no entanto, de modificar a "natureza" do criminoso, mas de educá-la de acordo com valores considerados moralmente sadios. Às instituições penais caberiam, então, um papel pedagógico; uma pedagogia toda ela construída sob o signo de uma ordem e uma disciplina que, ao agirem sobre os corpos, pretendem também a modelagem da alma. 
Neste sentido, a instalação da Penitenciária do Ahu segue muito de perto, ao menos teoricamente, os novos preceitos legais no que tangem à construção e funcionamento das instituições penais. O regulamento, organizado em três títulos, de forma a dar conhecimento dos deveres e atribuições da direção e dos funcionários (primeiro), do regime disciplinar e de trabalho dos condenados (segundo) e do regime econômico e serviços domésticos (terceiro e último), organiza o funcionamento do aparato técnico-burocrático da prisão. Como princípio geral a norteá-lo, um jogo que a um só tempo descentraliza e centraliza o poder, distribuindo-o, fazendo-o circular de forma que ele atravesse todo o corpo funcional guardas, carcereiros, amanuenses, médicos, enfermeiros, etc..., num fluxo contínuo, operacional e relacional de controle e vigilância.

À medida que se desloca das atribuições mais genéricas aquelas particulares, o regulamento se esmera, ainda em seu primeiro título, em ordenar e coordenar uma rede em que tudo das funções administrativas às oficinas de trabalho - convergem para aquele duplo efeito de que falei logo acima. Assim, de um lado mesmo aqueles que prestam serviço à penitenciária, sem serem a ela diretamente vinculados - caso dos mestres de oficina e do professor - têm suas obrigações e responsabilidades claramente definidas dentro da instituição. Nas salas de aula, por exemplo, o professor deve exercer a autoridade necessária para assegurar, desde a pontualidade e a freqüência, obrigatória, até o silêncio necessário durante as lições de leitura, escrita, aritmética elementar, noções rudimentares de gramática, noções de geografia e história do Brasil e dos direitos e deveres morais e políticos. Uma biblioteca, contendo livros de "leitura amena e edificante, para uso dos condemnados, segundo o grao de intelligencia e disposições moraes de cada um" ${ }^{20}$ estaria ainda sob a guarda do docente.

Por outro lado, tudo e todos dentro da instituição estão submetidos a autoridade vigilante e competente do diretor, cujas atribuições, muitas, fazem lembrar a onipresença e a onipotência do "Grande Irmão" orwelliano. Ele é ainda o elo 
entre a penitenciária e as autoridades públicas que, na hierarquia estatal, são as primeiras e principais responsáveis por ela. Informá-las por meio de estatísticas, números, mapas, comunicados e relatórios enviados periodicamente ao chefe de polícia - e deste ao secretário de Interior, Justiça e Instrução Pública e deste ainda ao Presidente do estado - é parte de suas "attribuições e deveres". ${ }^{21}$

Os dois capítulos seguintes - "Do regimen disciplinar e do trabalho" e "Regimen economico e serviço doméstico", respectivamente - esmiúçam, até ao detalhe, o aparato e as intenções disciplinares e pedagógicas da prisão. Tudo ali é expressão de um intuito, velado ou não, de gerir minuciosamente gestos, comportamentos e atitudes, por meio de uma racionalização do cotidiano transformado em uma rotina onde tudo e todos serão permanentemente administrados, vigiados e controlados. O trabalho compulsório, o silêncio, a uniformização das roupas e dos gestos, o isolamento noturno, os cuidados com a higiene, as sanções disciplinares, etc..., são fragmentos de uma prática que, ao inscrever-se na superfície dos corpos, tornando-os dóceis, obedientes e socialmente produtivos, pretende, como já dito, moldar pedagogicamente as almas.

Tal pretensão explica, em parte, o zelo com a vigilância, recorrente em todo o regulamento. Dentro e fora das celas - nos corredores, oficinas de trabalho, enfermarias, pátios, etc... - o trânsito dos condenados é supervisionado por uma pirâmide de olhares que não se esgota nos guardas e seu inspetor. Ela pode conter tanto os olhares dos mestres, professores ou enfermeiros - quando da permanência dos prisioneiros na escola, oficinas de trabalho ou na enfermaria, por exemplo -, quanto dos seus próprios companheiros, já que a estrutura da prisão incentiva, ainda que indiretamente, que os cativos espiem uns aos outros e a si mesmos. Essa miríade de olhos e olhares que de todos os lados e por todos os ângulos perscrutam corpos não é aleatória. Nas "Disposições gerais", em um dos artigos derradeiros do regulamento, lê-se que "Nos corredores e nas cellulas, haverá as luzes necessarias para que não escape á vigilancia dos guardas, 
qualquer movimento dos condemnados". ${ }^{22}$ O espaço físico da prisão adquire assim um caráter funcional graças às aspirações técnicas que inspiram sua organização. A intenção é tornar tudo e todos visíveis, submetidos a um olhar dominador e vigilante, incessante e intenso.

Parece claro que, entre outras, há a intenção intrínseca às prisões de, ao submeter os sentenciados a uma rotina de trabalho incessante, a uma disciplina contínua e a um controle constante, oferecer "em seu beneficio (...) um bom estímulo á sua regeneração". ${ }^{23}$ Mas esta leitura é ainda parcial e incompleta. Dentre as utilidades do regime penitenciário, está a que permite aos responsáveis pela ordem e a segurança subtrair do espaço público os indivíduos considerados nocivos, de uma degenerescência nômade, e fixá-los em um espaço onde são submetidos a um olhar capaz de tomá-los como objeto de um saber que pretende banir, do processo que transforma o criminoso em cidadão, todo o risco do acaso por meio de um domínio e de um controle totalitários do corpo. Marca-os, assim, com os sinais de uma identidade que deverá ser visível não apenas no ambiente fechado da prisão, mas no espaço aberto da cidade. Trata-se, em outros termos, de inscrever no corpo do sentenciado a marca de um estigma que o identificará, mesmo que longe do alcance da instituição, de forma que ele continue sendo o que na lógica asilar ele sempre foi e será: um paria (GOFFMAN, 1988).

A instituição penal atinge então seu fim último: não apenas regenerar, curar ou reintegrar o criminoso, mas produzir a delinqüência. Finalidade que justifica sua permanência em pleno século XXI, à revelia dos cada vez mais crescentes sinais de falência do projeto de que é o paradigma. Integra assim o crime e a criminalidade a um mecanismo moral e social fundado em uma norma da qual eles são, aparentemente, a negação: tornálos úteis e produtivos, "auxiliares da ordem". Utilidade que permite e justifica ações cada vez mais severas e generalizadas de controle e compartimentalização sociais na defesa contra o inimigo interno. A presença policial ostensiva, ela própria ameaçadora pela força repressiva e violenta de que é portadora, 
"UM BOM ESTÍMULO À REGENERAÇÃO": A PENITENCIÁRIA...

será abrandada pelos apelos constantes à insegurança e especialmente ao medo; medo alimentado pela iminência do ataque bárbaro às fronteiras da civilização.

\section{Referências Bibliográficas}

ALVAREZ, Marcos César. Bacharéis, criminologistas e juristas: saber jurídico e nova escola penal no Brasil. São Paulo: Método, 2003.

BENJAMIN, Walter. Paris no Segundo Império. In.: Charles Baudelaire, um lírico no auge do capitalismo (Obras escolhidas III). São Paulo: Brasiliense, 1989.

BERBERI, Elizabete. Impressões - a modernidade através das crônicas no início do século em Curitiba. Curitiba: Aos Quatro Ventos, 1998.

BURMESTER, Ana Maria de Oliveira. Disciplinarização e trabalho: Curitiba, fins do século XVIII, inícios do século XIX. História: Questões \& Debates. Curitiba, v. 8, n. 14-15, jul-dez. 1987.

CANCELLI, Elizabeth. Carandiru: a prisão, o psiquiatra e o preso. Brasília: Editora da UnB, 2005.

CANCELLI, Elizabeth. A cultura do crime e da lei. Brasília: Editora Universidade de Brasília, 2001.

CARVALHO, Elysio de. A polícia carioca e a criminalidade contemporânea. Rio de Janeiro: Imprensa Nacional, 1910.

CHAVES, João. Sciencia penitenciaria. Rio de Janeiro: Jacintho Ribeiro dos Santos Editor, 1923, pp. 205-209

Código Penal da República dos Estados Unidos do Brasil commentado por Oscar de Macedo Soares. Rio de Janeiro: Garnier, 1908.

DARMON, Pierre. Médicos e assassinos na Belle Époque. Rio de Janeiro: Paz e Terra, 1991.

D'ASSUMPÇÃO, Paulo. Histórico da força policial do Paraná. Curitiba: Typographia d'A República, 1909.

DE BONI, Maria Ignês Mancini. O espetáculo visto do alto: vigilância e punição em Curitiba (1890-1920). Curitiba: Aos Quatro Ventos, 1998.

FAUSTO, Boris. Crime e cotidiano: a criminalidade em São Paulo (18801924). São Paulo: Edusp, 2001.

FOUCAULT, Michel. Em defesa da sociedade. São Paulo: Martins Fontes, 2000. 
FOUCAULT, Michel. A verdade e as formas jurídicas. Rio de Janeiro: Nau Editora, 1996.

FOUCAULT, Michel. Microfísica do poder Rio de Janeiro: Graal, 1989.

FOUCAULT, Michel. Vigiar e punir: História da violência nas prisões. Petrópolis: Vozes, 1987.

GAROFALO, Raffaelle. Criminologia - Estudo sobre o delicto e a repressão penal. Lisboa: Typographia do Porto Medico, 1908.

GINZBURG, Carlo. Mitos, emblemas, sinais - morfologia e história. São Paulo: Companhia das Letras, 1989.

GOFFMAN, Erving. Estigma - Notas sobre a manipulação da identidade deteriorada. Rio de Janeiro: Guanabara, 1988.

GRUNER, Clóvis. Em torno à "boa ciência": debates jurídicos e a questão penitenciária na imprensa curitibana (1901-1909). Revista de História Regional. Ponta Grossa: UEPG, vol. 8, n. 1, verão 2003.

HAROCHE, Claudine; COURTINE, Jean Jacques. História do rosto Exprimir e calar as suas emoções (do século XVI ao início do século XIX). Lisboa: Teorema, 1995.

HERSCHMANN, Micael M.; PEREIRA, Carlos Alberto Messeder. O imaginário moderno no Brasil. In.: HERSCHMANN, Micael M.; PEREIRA, Carlos Alberto Messeder (Orgs.). A invenção do Brasil moderno: medicina, educação e engenharia nos anos 20-30. Rio de Janeiro: Rocco, 1994,

KARVAT, Erivan Cassiano. A sociedade do trabalho: discursos e práticas de controle sobre a mendicidade e a vadiagem em Curitiba, 1890-1933. Curitiba: Aos Quatro Ventos, 1998.

PEDROSO, Regina Célia. Utopias penitenciárias. Revista de História. São Paulo: USP, nr. 136, $1^{\circ}$ semestre de 1997.

PEREIRA, Magnus Roberto de Mello. Semeando iras rumo ao progresso: ordenamento jurídico e econômico da sociedade paranaense, 1829-1889. Curitiba: Editora da UFPR, 1996.

SALLA, Fernando. As prisões em São Paulo (1822-1940). São Paulo: Annablume/Fapesp, 1999.

STRAUBE, Ernani Costa. Polícia Civil - 150 anos. Curitiba: Edição do Autor, 2005. 
"UM BOM ESTÍMULO À REGENERAÇÃO": A PENITENCIÁRIA....

GRUNER, Clóvis. "A good stimulus to regeneration": the State Penitentiary and the new strategies of the order in Curitiba in the First Republic. História, v.28, n.2, p.421-448, 2009.

Abstract: Inaugurated in January of 1909, the Ahú Penitentiary, in Curitiba, is celebrated among the local authorities and elites as "an alive certificate of progress." It's project foresaw an orientation based on the modern penology regulations, that understood the imprisonment less as punishment and more as a possibility of physical and mainly, moral regeneration of the criminal. The aim of this essay is to follow the course that, from the first claims and complaints about the growth in rates of crime, culminates with the inauguration of the Penitentiary. The intention is, by comparing local sources - especially reports of police and government - with other ones, whose origin and repercussion surpasses the state limits - such as texts of jurists and criminologists -, to show that to show that the penal institution celebrated by the press and authorities from Paraná can only be understood if placed in a context that is not contained in the lines and between the speeches and policies strictly regional.

Keywords: Penitentiary; Discipline; Crime; Criminality.

\section{NOTAS}

${ }^{1} \mathrm{O}$ aumento no efetivo em todo o estado depois da proclamação da República é um indicativo dos investimentos do poder público visando uma melhor estrutura para a corporação policial. Em 1889 atuavam no Paraná 134 policiais; em 1890, completado o primeiro ano do novo regime, o número de policiais mais que dobrou, passando para 337. Em 1909, ano de inauguração da penitenciária, eram 703 atuando no estado em diferentes funções. (D'ASSUMPÇÃO, 1909).

2 HOSPICIO DE NOSSA SENHORA DA LUZ. Diário da Tarde. Curitiba, 25 mar. 1903. Ano V, n. 1235, p. 1. 
${ }^{3}$ A MENDICIDADE. Diário da Tarde. Curitiba, 26 mar. 1903. Ano V, n. 1236, p. 1. O recolhimento e conseqüente prisão dos mendigos constavam do Código Penal de 1890, que tratava do crime e das penas relativas à mendicidade no Livro III ("Das contravenções em espécie"), Capítulo XII ("Dos mendigos e ebrios"), artigos 391 a 396. Sobre o controle da mendicidade em Curitiba, ver: KARVAT, 1998.

4 Em 1880 um projeto de construção da primeira penitenciária estadual chegou a ser formulado. O lançamento da pedra inaugural contou, inclusive, com a presença de D. Pedro II, que em maio daquele ano aproveitou a passagem por algumas cidades do Paraná, Curitiba entre elas, para inaugurar uma série de obras, tais como estradas e escolas, além da futura instituição penal. Assinado pelo engenheiro Francisco Antonio Monteiro Tourinho, o projeto era "delineado no estylo panoptico" e inspirado na "casa de correcção da Côrte (...) que (...) iguala em perfeição os melhores modelos que a Inglaterra e os Estados Unidos offerecem no gênero das prisões cellulares." Apesar de arrojado e moderno, nem mesmo as bênçãos do imperador asseguraram a continuidade da obra, paralisada pelas condições financeiras difíceis da província. Cf.: Descripção e orçamento do Projecto da Penitenciária de Curityba pelo Engenheiro Francisco Antonio Monteiro Tourinho, apresentado ao Presidente da Província Manuel Pinto de Souza Dantas Filho em 8 de julho de 1880.

${ }^{5}$ Relatório ao Secretário do Interior, Justiça e Instrucção Pública do Paraná, Dr. Antônio Augusto Chaves, pelo Major Augusto Silveira de Miranda, Chefe de Polícia interino do Estado, 1898.

${ }^{6}$ Relatório apresentado ao Presidente do Estado, Dr. Francisco Xavier da Silva, pelo Secretário do Interior, Justiça e Instrucção Pública do Paraná, Dr. Octávio Ferreira do Amaral e Silva, 1900.

${ }^{7}$ ERASTO. "Conversando". Diário da Tarde. Curitiba, 29 de abril de 1902. Ano IV, n. 959, p. 1.

8 Entre outras coisas, o Código republicano aboliu a prisão perpétua, a pena de morte e as demais chamadas "penas infamantes" em seus artigos 43 e 44 . Estabeleceu também como pena máxima, no artigo 294, a prisão celular de 30 anos para crime de homicídio com agravante. 
"UM BOM ESTÍMULO À REGENERAÇÃO": A PENITENCIÁRIA...

${ }^{9}$ Código Penal do Brazil, Livro I ("Dos crimes e das penas"), Título V ("Das penas e seus effeitos; da sua applicação e modo de execução"), artigos 43 a 45 e 53.

10 Tomo emprestado de Boris Fausto a distinção entre "crime" e "criminalidade" que emprego aqui. Para Fausto, criminalidade "se refere ao fenômeno social na sua dimensão mais ampla, permitindo - estabelecimento de padrões através da constatação de regularidades e cortes"; ao passo que crime remete "ao fenômeno na sua singularidade, cuja riqueza em certos casos não se encerra em si mesma, como caso individual, mas abre caminho para muitas percepções" (FAUSTO, 2001: 19).

${ }^{11}$ ESTADO DO PARANÁ. Decreto n. 611, de 6 de abril de 1905. Concede ao Estado autorização para aquisição da Santa Casa de Misericórdia. Curitiba, 1905.

${ }_{12}$ Mensagem ao Congresso Legislativo do Estado do Paraná dirigido pelo Dr. Vicente Machado da Silva Lima, Presidente do Estado. Curitiba: Typografia da Livraria Econômica, 1905.

${ }^{13}$ Relatório apresentado ao Vice-Presidente do Estado, Dr. Joaquim Monteiro de Carvalho e Silva, pelo Secretário do Interior, Justiça e Instrucção Pública do Paraná, Bacharel Bento José Lamenha Lins, 1907.

${ }^{14}$ ESTADO DO PARANÁ. Decreto n. 564, de 23 de setembro de 1908. Regulamento da Penitenciária do Estado. Curityba: Typographia d'Republica, 1908.

${ }^{15}$ Relatório apresentado ao Exmo. Snr. Dr. Francisco Xavier da Silva, Presidente do Estado do Paraná, pelo Bacharel Claudino Rogoberto Ferreira, Secretário d'Estado dos Negócios de Obras Públicas e Colonisação, 1909. Os grifos são meus.

${ }^{16}$ Relatório apresentado ao Exmo. Sr. Francisco Xavier da Silva, Presidente do Estado, pelo Coronel Luiz A. Xavier, Secretário do Interior, Justiça e Instrucção Pública, 1909.

${ }^{17}$ Relatório apresentado ao Exmo. Sr. Dr. Francisco Xavier da Silva, Presidente do Estado, pelo Desembargador Procurador Geral de Justiça, José Maria Pinheiro Lins, 1910.

${ }_{18}$ Relatório do Director da Penitenciária do Ahu, Major Ascanio Ferreira de Abreu ao Chefe de Polícia, Desembargador João Batista da Costa Carvalho Filho, 1909. 
19 Relatório do Director da Penitenciária do Ahu, Major Ascanio Ferreira de Abreu ao Chefe de Polícia, Desembargador João Batista da Costa Carvalho Filho, 1909.

${ }^{20}$ Artigos 50 a 54 do Capítulo IV ("Das attribuições e deveres do Director"), Título I ("Do pessoal. Suas atribuições").

${ }^{21}$ Que constam, mais especificamente, nos itens I, VIII, XI, XII, XV, XVI, XVII, XX, XXIII, XXVI, XXVII e XXXII do artigo 17 do Capítulo IV ("Das attribuições e deveres do Director"), Título I ("Do pessoal. Suas atribuições").

22 Artigo 206, Capítulo XXVII ("Disposições Geraes"), Título III ("Regimen economico e serviço domestico").

23 Relatório apresentando ao Exmo. Sr. Dr. Francisco Xavier, Presidente do Estado, pelo Coronel Luiz A. Xavier, Secretario do Interior, Justiça e Instrução Pública, 1910.

Artigo recebido em 04/2009. Aprovado em 09/2009. 